\title{
CARACTERIZAÇÃO DE UM AÇO INOXIDÁVEL DUPLEX EM COMPARAÇÃ̃O A AÇOS INOXIDÁVEIS FERRITICOS E AUSTENÍTICOS EM RELAÇÃO À MICROESTRUTURA E PROPRIEDADES MECÂNICAS EM TRAÇÃO*
}

\author{
Marcela Alves Silva ${ }^{1}$ \\ Beatriz Araújo Batista ${ }^{2}$ \\ Luana Araújo Batista ${ }^{3}$
}

\section{Resumo}

Aços inoxidáveis são ligas $\mathrm{Fe}-\mathrm{C}-\mathrm{Cr}$ com elevada resistência à corrosão. Estes podem receber diferentes elementos de liga, que alteram suas microestruturas e propriedades de acordo com o interesse da aplicação. Os mais comuns são os austeníticos, ferríticos, martensíticos e duplex. Os aços inoxidáveis austeníticos possuem excelente resistência à corrosão, elevada ductilidade, boa soldabilidade, conformabilidade e tenacidade. Os aços inoxidáveis ferríticos possuem boa resistência à corrosão, são bons para estampagem e possuem maior dureza e soldabilidade em relação aos austeníticos. Os aços inoxidáveis duplex (AID) são aços com estrutura bifásica, formados pelas fases ferrita e austenita, em proporções de aproximadamente $50 \%$ de cada. Os AIDs apresentam associação de resistência mecânica com resistência à corrosão. $O$ presente trabalho tem como objetivo realizar ensaios metalográficos e tração de um AID 399B, de um aço inoxidável ferrítico 441A e de um aço inoxidável austenítico $304 \mathrm{~N}$, para fins de comparação da microestrutura e propriedades mecânicas. Com os resultados conclui-se que o AID possui maior resistência à dureza na escala HRB, o aço austenítico possui maior capacidade de alongamento, devido sua estrutura CFC. Já o limite de resistência e de escoamento são maiores no aço AID devido a sua maior proporção da fase ferrita (52\%).

Palavras-chave: Aços inoxidáveis duplex; Estrutura bifásica; Resistência à corrosão.

\section{CHARACTERIZATION OF STAINLESS STEEL DUPLEX IN COMPARISON AÇOS FERRITIC AND AUSTENITIC REGARDING THE MICROSTRUCTURE AND MECHANICAL PROPERTIES IN DRAW}

\begin{abstract}
Stainless steels are $\mathrm{Fe}-\mathrm{C}-\mathrm{Cr}$ alloys with high corrosion resistance. These can receive different alloying elements, which alter their microstructures and properties according to the application of interest. The most common are austenitic, ferritic, martensitic and duplex. The austenitic stainless steels have excellent corrosion resistance, high ductility, good weldability, formability and toughness. Ferritic stainless steels have good corrosion resistance, higher toughness and lower formability, welding compared to austenitic and are good for printing. Duplex stainless steels (DSS) are steels having a biphasic structure formed by ferrite and austenite phases in proportions of approximately $50 \%$ each. DSSs have mechanical strength of association with corrosion resistance. This study aims to conduct metallographic testing and draw a DSS 399B, a ferritic stainless steel $441 \mathrm{~A}$ and an austenitic stainless steel $304 \mathrm{~N}$, for comparison of microstructure and mechanical properties. From the results it is concluded that DSS has higher resistance HRB in hardness scale, the austenitic steel has higher elongation, because CFC their structure. But the strength and yield strength are higher in duplex steel due to its higher proportion of ferrite phase $(52 \%)$..

Keywords: Duplex stainless steels; Biphasic structure; Corrosion resistance.

1 Graduanda em Engenharia Metalúrgica, Centro Universitário do Leste de Minas Gerais - Unileste, Coronel Fabriciano, Minas Gerais, Brasil.

2 Graduanda, Eng. Metalúrgica, Centro Universitário do Leste de Minas Gerais - Unileste, Coronel Fabriciano, MG, Brasil.

3 Mestranda, Eng. Metalúrgica, Universidade Federal de Minas Gerais, Belo Horizonte, MG, Brasil.
\end{abstract}




\section{INTRODUÇÃO}

Aços inoxidáveis são ligas de Fe-C-Cr com no mínimo de $10,5 \%$ de cromo, que possuem elevada resistência à corrosão [1]. Além do cromo podem ser adicionados outros elementos químicos, a fim de melhorar determinadas propriedades do material. Dentre os tipos de aços inoxidáveis produzidos estão os aços inoxidáveis austeníticos, ferríticos e duplex.

Os aços inoxidáveis austeníticos possuem além do cromo a adição de níquel, o que Ihes garante uma estrutura CFC (Cúbica de Face Centrada). Esses aços são nãomagnéticos, com excelente resistência à corrosão e propriedades mecânicas como elevada ductilidade, boa soldabilidade, conformabilidade e tenacidade [2].

Os aços inoxidáveis ferríticos podem ser estabilizados com titânio, nióbio e vanádio, o que lhes conferem aumento na resistência à corrosão e mecânica. Com estrutura CCC (Cúbica de Corpo Centrada), esses aços são magnéticos, de boa resistência à corrosão e suas propriedades mecânicas mais marcantes são: maior dureza e menores conformabilidade e soldagem, em relação aos austeníticos, e boa estampabilidade. São mais utilizados para aplicações que não exigem que o material seja soldado [2] [3].

Os aços inoxidáveis duplex (AID) são aços com estrutura bifásica, formada pelas fases ferrita e austenita, sendo que a proporção delas deve ser aproximadamente igual. A microestrutura $50 \%$ ferrita - $50 \%$ austenita é conseguida através do controle dos elementos de liga. O níquel, o carbono e o nitrogênio estabilizam a austenita, já o cromo, o molibdênio e o silício estabilizam a fase ferrita [2].

Os aços duplex são endurecíveis por tratamento térmico, tornando-se mais resistentes que os aços ferrríticos e austeníticos na condição recozida e dispõe de limite de escoamento médio em torno de $450 \mathrm{MPa}$. Como os aços ferríticos, estes aços são ferromagnéticos, e, já a boa conformabilidade e soldabilidade, vem dos aços austeníticos [2].

O comportamento dos aços duplex está ligado diretamente com as características de cada fase. A austenita possibilita alongamento, já a ferrita propicia um elevado nível de escoamento. Por isso, para maximizar as propriedades de cada uma dessas fases, é importante manter o balanceamento entre elas [4].

A vantagem dos duplex sobre os austeníticos e os ferríticos é a resistência mecânica e uma maior resistência à corrosão por cloretos e sob tensão. Por isto, analisandose o custo-benefício, o duplex é mais barato do que outros materiais utilizados em ambientes corrosivos, como por exemplo, ligas de níquel.

O objetivo deste trabalho é medir propriedades como ductilidade, alongamento, tenacidade e elasticidade, através do ensaio de tração e metalografia de um aço inoxidável duplex 399B, de um aço inoxidável ferrítico 441A e de um aço inoxidável austenítico $304 \mathrm{~N}$, para fins de comparação da microestrutura e propriedades citadas.

\section{MATERIAIS E MÉTODOS}

Para a realização da análise, o plano de interesse da amostra é cortado, lixado, polido e atacado com reagente químico, de modo a revelar as interfaces entre os diferentes constituintes que compõe o metal. Quanto ao tipo de observação, está subdividida, basicamente em duas classes: microscopia e macroscopia. As análises deste trabalho foram realizadas através de microscopia óptica. 
As análises das estruturas metalográficas das amostras dos aços austenítico (304), ferrítico (441) e duplex (399) foram realizados conforme as etapas apresentadas.

\section{- Retirada e Identificação das amostras}

Foram retiradas, de bobinas após laminação a frio, uma amostra de cada material, de dimensões conforme a Tabela 1.

Tabela 1. Dimensões das amostras

\begin{tabular}{lccc}
\hline & Austenitico & Ferrítico & Duplex \\
\hline Aço & 304 & 441 & 399 \\
Espessura (mm) & 2,0 & 1,8 & 1,8 \\
Largura (mm) & 1240 & 1200 & 680 \\
\hline
\end{tabular}

\section{- Corte das amostras}

Foi realizado o corte das amostras a partir da máquina Radiac de discos abrasivos.

\section{- Embutimento das amostras}

As amostras cortadas foram colocadas na embutidora, onde foram embutidas em um molde de resina. Ficaram por sete minutos para aquecimento e quatro minutos para resfriamento. Esta etapa destinou-se apenas para as amostras que foram analisadas no microscópio óptico.

\section{- Lixamento e Polimento}

Inicialmente foi feito o lixamento com cinco lixas d'água (120, 220, 320, 500 e 600) e em seguida polimento com pano $(9 \mu)$ e pasta de diamante. Gerando como resultado uma superfície espelhada e brilhante. Esta etapa destinou-se apenas para as amostras que foram analisadas no microscópio óptico.

\section{- Ataque Metalográfico}

Para revelar as microestruturas estudadas foi necessário atacar com diferentes soluções, de acordo com o aço trabalhado, 399B: Behara modificado; 441: cloreto férrico e ácido clorídrico; 304: Glicerina mais água régia.

\section{- Análise Metalográfica}

Para a análise da estrutura metalográfica das amostras dos aços foi feita análise comparativa, utilizado um microscópio óptico.

\section{- Ensaio de tração}

Para os ensaios de tração foi utilizada uma Máquina Universal de ensaios. 
Para as análises de dureza, utilizou-se o método Rockwell na escala $B$ (HRB), onde se leva em consideração a resistência a endentação do material por esferas de aço de alta dureza e pré carga de $10 \mathrm{Kgf}$, conforme a norma ASTM E18.

\section{RESULTADOS E DISCUSSÃO}

Encontram-se abaixo, as micrografias das amostras, onde a Figura 2 apresenta a estrutura Ferrítica, a Figura 3 apresenta à estrutura austenítica e a Figura 4 a estrutura Duplex.

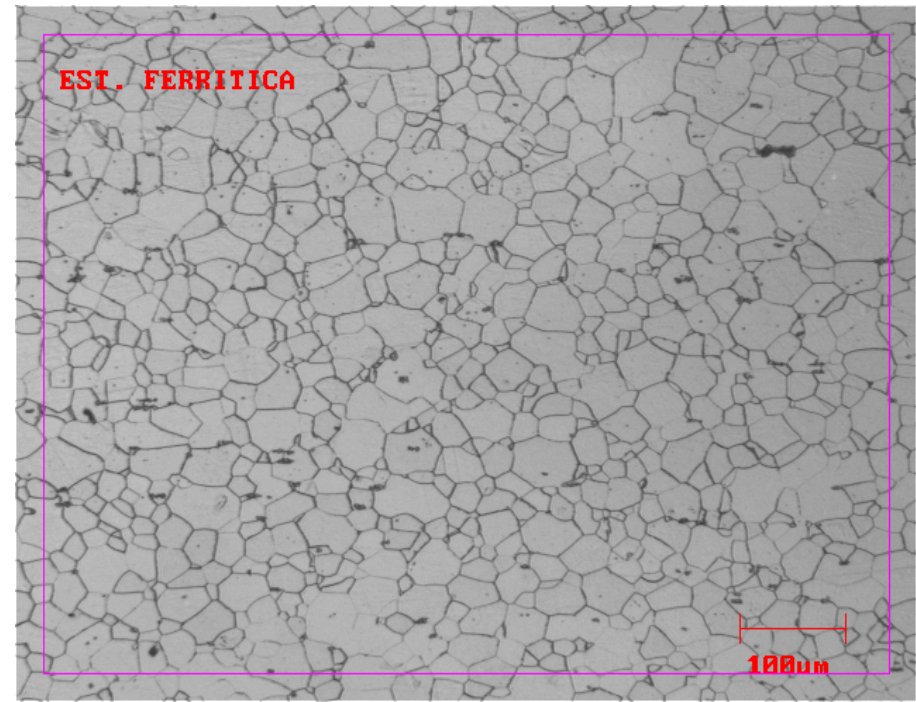

Figura 2. Microestrutura ferrítica do aço 441 com ampliação de 100x.

Na Figura 2, observa-se uma típica estrutura ferrítica com um pouco de fase acicular precipitada nos contornos de grão na forma de precipitados escuros. Verifica-se uma estrutura ferrítica completamente recristalizada com grãos grandes.

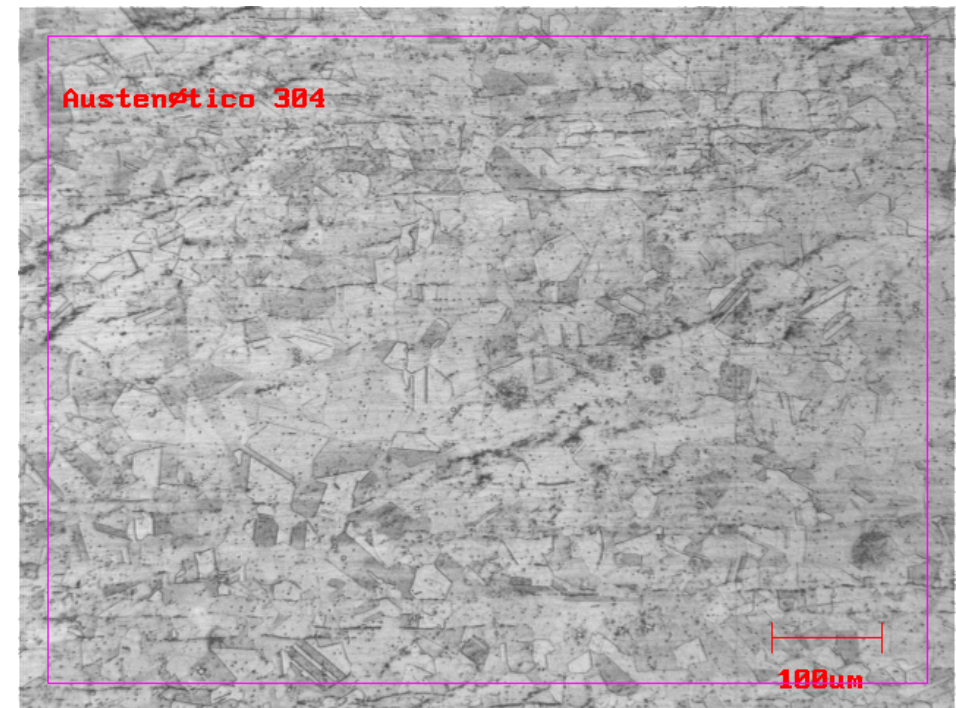

Figura 3. Microestrutura austenítica do aço 304 com ampliação de 100x.

Na Figura 3, é observada uma estrutura austenítica com precipitados escuros. Pela característica alinhada dos precipitados sobre as linhas de deformação, acredita-se que sejam constituídas por ferrita delta, formada no processo de laminação a quente do material. 


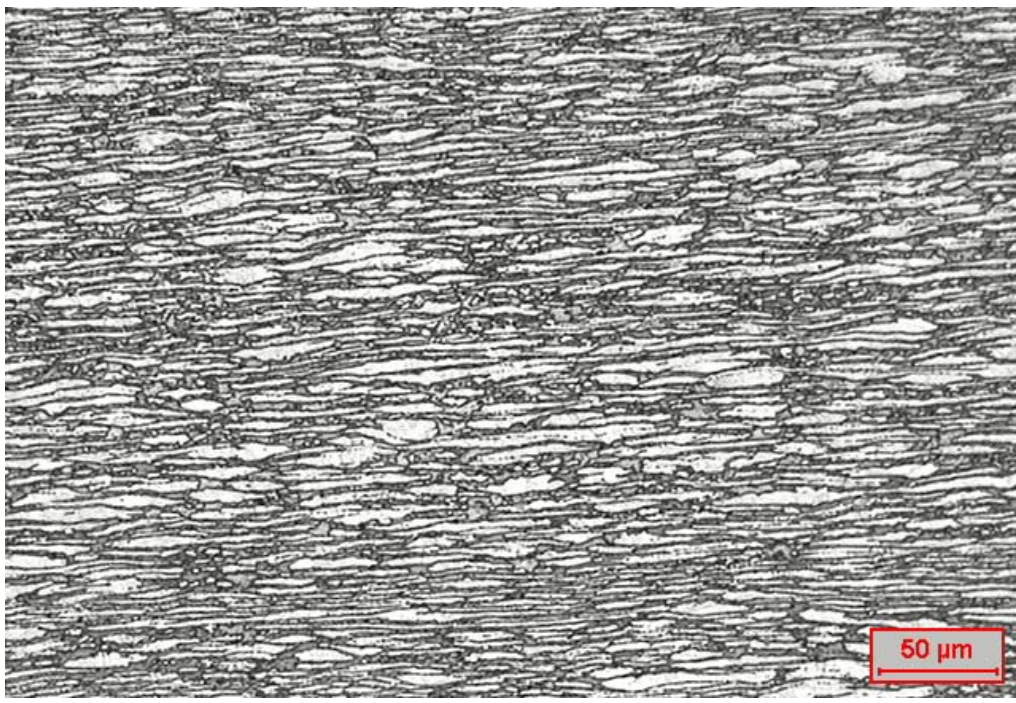

Figura 4. Microestrutura Duplex do aço 399B com ampliação de 200x.

Com o auxílio do software Quantikov calculou-se a proporção das fases no AID, onde a região atacada escura representa a fase ferrítica (52\%), e a região atacada clara representa a fase austenítica (48\%), conforme a Figura 4.

A formação de sua estrutura duplex se dá pela solidificação de uma microestrutura completamente ferrítica e a precipitação da austenita nos contornos de grão da ferrita. Como a partição dos elementos entre as fases é conduzida pelo fenômeno da difusão, o coeficiente de partição depende da taxa de resfriamento a que é submetido o aço, e da influência dos elementos alfagênicos e gamagênicos.

Foram realizados ensaios de tração e obtidos resultados das propriedades mecânicas dos três aços, com o qual, montou-se a Tabela 2.

Tabela 2. Propriedades mecânicas das amostras

\section{Propriedades Mecânicas}

\begin{tabular}{cccccc}
\hline Tipo & Aço & $\begin{array}{c}\text { Dureza } \\
\text { HRB }\end{array}$ & $\begin{array}{c}\text { Limite de } \\
\text { Resistência (MPa) }\end{array}$ & $\begin{array}{c}\text { Limite de Escoamento } \\
\mathbf{0 , 2}(\mathbf{M P a})\end{array}$ & $\begin{array}{c}\text { Alongamento } \\
\text { (\%) }\end{array}$ \\
Ferrítico & 441 & 77 & 557 & 288 & 40 \\
Austenítico & 304 & 71 & 566 & 299 & 59 \\
Duplex & 399 & 101 & 839 & 688 & 29 \\
\hline
\end{tabular}

Com os valores obtidos, foram realizadas comparações das propriedades mecânicas dos aços 304 (Austenítico), 441(Ferrítico) e 399 (Duplex). Verificou-se primeiramente que o aço duplex apresentou maior dureza do que os demais, como era esperado. $E$ que as durezas resultantes dos aços austenítico e ferrítico foram muito próximas.

Constatou-se que o limite de resistência do duplex foi cerca de $50 \%$ maior do que dos aços monofásicos. Assim como o limite de elasticidade muito superior, tendo o valor maior do dobro dos demais. O que justifica a aplicação do duplex em aplicações de grande responsabilidade, com exigência de alta resistência mecânica, como na fabricação de tubos para a indústria off-shore.

Ao contrário das demais propriedades em termos de alongamento o duplex possuiu menor valor do que os outros aços estudados, o que era esperado devido ao elevado valor de elasticidade. Outra observação é o maior alongamento do aço austenítico em relação ao ferrítico, que reflete na maior estampabilidade deste aço. Fazendo-o ser mais indicado para aplicações em estampagem profunda. 


\section{CONCLUSÃO}

O aumento da utilização dos aços inoxidáveis duplex em ambientes de condições extremas, como altas pressões e atmosferas oxidantes, é devido as suas excelentes propriedades de resistência mecânica e à corrosão nestes ambientes. Os aços inoxidáveis duplex apresentam estrutura formada pelas fases austenita e ferrita, em proporções aproximadamente iguais, garantindo superiores propriedades mecânicas e resistência à corrosão. O que lhe garante excelente relação de custo-benefício na sua aplicação em ambientes corrosivos em relação a outros materiais.

Com os ensaios metalográficos, é possível fazer um comparativo das fases austenita e ferrita, assim como verificá-las distintamente no aço duplex. Por apresentarem composições químicas diferentes, assim como estrutura cristalina, os referidos aços apresentam diferentes propriedades mecânicas o que pode ser medido pelo ensaio de tração.

Nota-se a partir dos resultados, que o aço duplex possui um maior valor de resistência à dureza na escala $H R B$, já o aço austenítico possui uma maior capacidade de alongamento, devido sua estrutura CFC. Já o limite de resistência e o limite de escoamento são maiores no aço duplex devido a sua maior proporção da fase ferrita $(52 \%)$.

\section{REFERÊNCIAS}

1 ABINOX. COLETÂNEA DE INFORMAÇÕES TÉCNICAS - AÇO INOXIDÁVEL Tipos de Aços Inoxidáveis. Disponível em:<http://www.abinox.org.br/upfiles/arquivos/biblioteca/ tipos-de-acos-inoxidaveis.pdf>. Acesso em: 21 de Outubro de 2015.

2 PEREIRA, Patricia Apicelo de Souza. Efeito da energia de soldagem na microestrutura de um aço inoxidável duplex e superduplex. Disponível em:<http://uenf.br/posgraduaca o/engenharia-e-materiais/wp-content/uploads/sites/2/2013/07/Mestrado.pdf>. Acesso em: 20 de Novembro de 2015.

3 SENATORE, Marcelo. Estudo comparativo entre os aços inoxidáveis dúplex e os inoxidáveis AISI 304L/316L. Disponível em:<http://www.scielo.br/scielo.php?pid=S03 70-44672007000100027\&script=sci_arttext>. Acesso em: 20 de Outubro de 2015.

4 ASSOCIAÇÃO BRASILEIRA DO AÇO INOXIDÁVEL. ABC do Aço Inox. Disponível em:<http://www.abinox.org.br/aco-inox-abc-do-aco-inox.php>. Acesso em: 18 Março de 2016. 